\title{
HORMIGÓN AUTORREPARABLE CON BACTERIAS Y REFORZADO CON FIBRAS NATURALES: PRINCIPIOS Y APLICACIONES EN ECUADOR
}

\author{
SELF-HEALING CONCRETE WITH BACTERIA AND REINFORCED WITH \\ NATURAL FIBERS: PRINCIPLES AND APPLICATIONS IN ECUADOR
}

GUADALUPE SIERRA', WALTER MERA², HENK JONKERS ${ }^{3}$

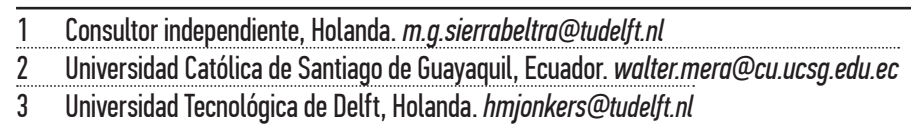

2 Universidad Católica de Santiago de Guayaquil, Ecuador. walter.mera@cu.ucsg.edu.ec

3 Universidad Tecnológica de Delft, Holanda. hmjonkers@tudelft.nl

Durante su vida útil las estructuras de hormigón sufren agrietamientos por diversas causas. A través de las grietas, oxígeno, agua, cloruros y otros agentes agresivos pueden penetrar para detrimento de la durabilidad del hormigón, de su comportamiento y de su vida útil. El hormigón posee una capacidad innata de reparación. Sin embargo, esta capacidad es limitada y dependiendo de las condiciones ambientales a las que se exponga el material y a su composición, el tamaño de grietas que pueden ser auto-reparadas será de máximo $0.6 \mathrm{~mm}$. En la Universidad Tecnológica de Delft se ha investigado el uso de bacterias en el hormigón, a fin de incrementar la capacidad de reparación mediante el uso de precipitación microbiana inducida (conocida como MIP por sus siglas en inglés). Este método se basa en la precipitación localizada de carbonatos de calcio (CaCO3) inducida por actividad bacteriana. El principio de MIP en grietas en hormigón fue probado en laboratorio y luego aplicado al desarrollo de diversos materiales autorreparables. En este trabajo se describen los principios de la MIP y la aplicación de hormigón autorreparable reforzado con fibras naturales en canales de irrigación en la provincia de Tungurahua, Ecuador. Esta fue la primera aplicación en el mundo de un hormigón autorreparable con bacterias.

PALABRAS CLAVE: hormigón, autorreparación, bacterias, fibras.

\section{ABSTRACT}

During their whole existance, concrete structures are cracked for various reasons. Through cracking, oxygen, water, chlorides and other aggressive agents can penetrate to the detriment of the durability of the concrete, its behavior and its useful life. Concrete has an innate capacity for repair. However, this capacity is limited and depending on the environmental conditions to which the material is exposed and its composition, the size of cracks that can be self-repaired will be a maximum of $0.6 \mathrm{~mm}$. At the Delft University of Technology, the use of bacteria in concrete has been investigated in order to increase the capacity for repair through the use of induced microbial precipitation (known as MIP). This method is based on the localized precipitation of calcium carbonates ( $\mathrm{CaCO}$ ) induced by bacterial activity. The principle of IPM in cracks in concrete was tested in the laboratory and then applied to the development of various self-repairing materials. This paper describes the principles of IPM and the application of self - reinforcing concrete reinforced with natural fibers in irrigation canals in the province of Tungurahua, Ecuador. This was the first application in the world of a self-healing concrete with bacteria.

KEYWORDS: concrete, self-repair, bacteria, fibers. 


\section{INTRODUCCIÓN}

Durante su vida útil, las estructuras de hormigón sufren agrietamientos por diversas causas, siendo los motivos más comunes: la contracción por fraguado, la expansión térmica, el esfuerzo por carga y la fluencia. Aun cuando el agrietamiento es un fenómeno tan común y a pesar que un agrietamiento no necesariamente implica daño estructural, por motivos estéticos o psicológicos para el usuario las grietas no son deseables. Además, el agrietamiento contribuye a la disminución de la durabilidad. Grietas muy finas pueden permitir el ingreso de oxígeno, agua, cloruros $u$ otros agentes agresivos que contribuyen a la corrosión del acero de refuerzo y, de esta manera, a la disminución de la durabilidad, la capacidad de carga y la vida útil de una estructura de hormigón. Este artículo detalla el uso de un agente bacteriano para incrementar la capacidad de autorreparación del hormigón, luego del agrietamiento. El principio de autorreparación con bacterias fue extensamente estudiado experimentalmente y luego aplicado satisfactoriamente en campo, en la provincia de Tungurahua, Ecuador, en julio de 2014.

\section{BACTERIA COMO AGENTE DE AUTORREPARACIÓN}

El hormigón tiene la capacidad innata de reparar agrietamientos (De Rooij et al. 2013, Neville 2002, Edvardsen 1999). De acuerdo a De Rooij (2013), es posible considerar una recuperación ante una acción ambiental como una reparación en hormigón, si el espesor a lo largo de la grieta disminuye con el tiempo. La reparación autógena se da por diferentes fenómenos, entre ellos los más comunes son: la continuación de hidratación del cemento y la precipitación del carbonato de calcio en las grietas, en un proceso similar a la carbonatación. En la actualidad, especialmente, los hormigones de alta resistencia se preparan con una relación agua/cemento baja (menor a 0.30); quedando dentro del hormigón fraguado partículas de cemento sin hidratar, las mismas que, ante la presencia de un agrietamiento e ingreso de agua, pueden continuar su hidratación. Sin embargo, el espesor de grieta que puede repararse de manera autógena es menor a $0.17 \mathrm{~mm}$, según los resultados de diferentes estudios (Palin et al. 2015, Huang et al. 2013, Schlangen y Joseph 2009, Yang et al. 2009, Qian et al. 2007). Recientemente, una investigación mostró el potencial de reparación autógena en hormigón sumergido en agua marina artificial, donde se observaron el cierre de grietas de hasta $0.59 \mathrm{~mm}$ de espesor (Palin et al. 2015).
A fin de incrementar la capacidad autógena de reparación del hormigón se pueden incorporar agentes específicos a la mezcla, tales como: polímeros súper absorbentes (Snoeck et al. 2012, Kim y Schlangen 2011), agentes expansivos y geomateriales (Ahn y Kishi 2009 y 2010), agentes líquidos encapsulados

(Huang y Ye 2011, Pelletier et al. 2010) o bacterias encapsuladas (Jonkers 2011, Wang 2013, Sierra Beltrán et al. 2014a, b). Si se seleccionan adecuadamente las bacterias es posible lograr una precipitación microbiana inducida (MIP por sus siglas en inglés) de minerales compatibles con el hormigón en las grietas.

Se puede lograr MIP de diferentes maneras, siendo la más usual hasta ahora la degradación de urea en un ambiente rico en calcio. Este es un proceso de fácil control y en el que se obtiene una cantidad considerable de carbonato de calcio (Van Titelboom et al. 2010, Dhami et al. 2012, Wang 2013). Las bacterias descomponen la urea y producen amonio, disuelven carbón inorgánico e incrementan el $\mathrm{pH}$, lo cual favorece la precipitación de carbonato de calcio $\left(\mathrm{CaCO}_{3}\right)$. Sin embargo, este sistema genera problemas ambientales por la producción de amonio.

Otro sistema para obtener MIP es el uso de bacterias que mediante una conversión de lactato de calcio den lugar a la precipitación de calcita. Este método, que no involucra la hidrólisis de la urea, es el método descrito empleado en este artículo. Se eligieron bacteria del género Bacillus, específicamente de la especie B.cohnii (Spanka y Fritze 1993) que fueron aisladas de muestras de suelo alcalino (Jonkers et al. 2010). Estas bacterias tienen la capacidad de formar esporas y alcalifílicas (prefieren las condiciones alcalinas). Se eligió como alimento para estas bacterias una solución de lactato de calcio y extracto de levadura. Ante la presencia de agua, las bacterias son capaces de reparar grietas en hormigón mediante la formación directa e indirecta de carbonato de calcio $\left(\mathrm{CaCO}_{3}\right)$, tal como se describe en la figura 1 (Jonkers 2011). La formación directa es similar al proceso conocido como carbonatación.

Como agente para incrementar la capacidad de autorreparación, las bacterias y su alimento deben incorporarse a la mezcla fresca de hormigón y deben permanecer en estado inactivo en el hormigón endurecido hasta que se presente el agrietamiento. Para ello es necesario inmovilizar las bacterias dentro de algún tipo de partícula. A fin de extender la vida útil de este agente, las bacterias se incorporan como 
esporas y no como bacterias. Las esporas son células especializadas esféricas de paredes gruesas, comparables a las semillas de una planta. Estas esporas son células viables, pero en estado inactivo.

Pueden soportar esfuerzos mecánicos y químicos y mientras no estén secas permanecerán viables por periodos de más de 50 años (Jonkers, 2011).

Las esporas de bacteria y el alimento seleccionado (lactato de calcio y extracto de levadura) se impregnan dentro de partículas de arcilla expandida. Este tipo de agregado ligero es un portador adecuado para poder incorporar el agente de autorreparación (bacterias) durante la mezcla fresca. Las arcillas expandidas no se rompen durante la mezcla. Adicionalmente, gracias a una buena adhesión con el hormigón, al momento del agrietamiento las partículas se fracturan dejando expuesto el agente de autorreparación que está inmovilizado dentro.

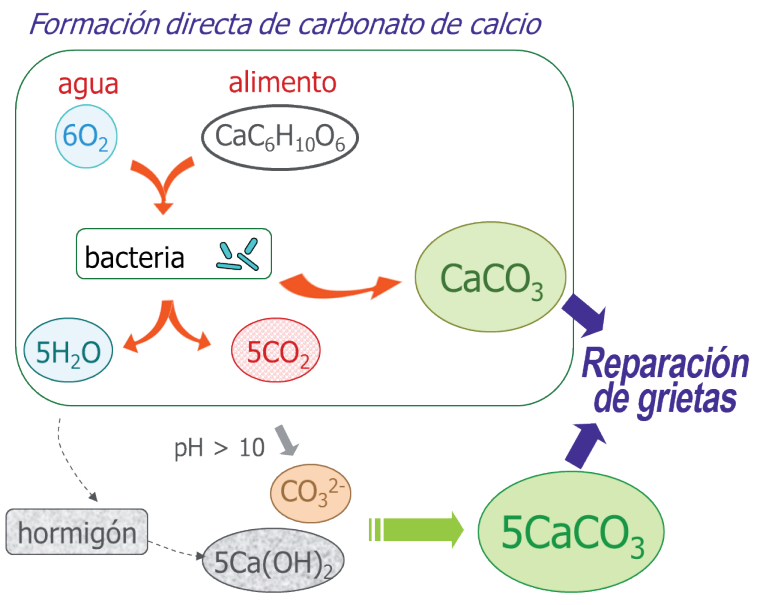

Formación indirecta de carbonato de calcio

Figura 1. Formación directa y formación indirecta de carbonato de calcio para reparación de grietas.

En investigaciones preliminares se realizaron pruebas de laboratorio preparando morteros, en los que se reemplazó el 50\% del volumen total de los agregados con arcillas expandidas (Jonkers 2011, Wiktor y Jonkers 2011). Debido al alto porcentaje de reemplazo con partículas de peso y resistencia ligeros, el esfuerzo de compresión a los 28 días de los morteros disminuyó con respecto al obtenido con morteros elaborados sin reemplazo. Sin embargo, la capacidad de autorreparación de los morteros con bacterias se incrementó sustancialmente, comparada con la capacidad de los morteros con arcillas expandidas sin impregnar. La capacidad de autorreparación fue evaluada en la investigación presentada por Jonkers (2011) mediante pruebas de permeabilidad e imágenes en el microscopio.

\section{DESCRIPCIÓN DEL PROBLEMA}

En la provincia del Tungurahua, en Ecuador, hace aproximadamente 100 años, el dueño de una extensa propiedad construyó un canal a fin de llevar aguas de deshielo desde las montañas Carihuairazo y Chimborazo hasta los valles de cultivos de su propiedad. Este canal, de tierra compactada, transportaba agua a lo largo de 24 kilómetros, desde una altura de aproximadamente 3200 m.s.n.m. hasta 2700 m.s.n.m. En esta región las temperaturas oscilan entre $5^{\circ} \mathrm{C}$ y $20^{\circ} \mathrm{C}$, pudiendo en ocasiones bajar a $0^{\circ} \mathrm{C}$. Durante los años 60 estas tierras fueron repartidas entre los agricultores que las trabajaban y el canal pasó a ser propiedad de esta comunidad. Durante décadas el canal cumplió sus funciones pero de manera poco eficiente. Aproximadamente $70 \%$ del agua se perdía por evaporación o infiltración al suelo. A fin de mejorar la eficiencia del canal, hace cuatro años los agricultores, junto con las autoridades locales, unieron esfuerzos para revestir el canal con hormigón sin refuerzo. En menos de un año este recubrimiento de hormigón presentó agrietamientos. Este agrietamiento originó, nuevamente, la disminución del agua transportada. Además, las grietas podían representar un riesgo estructural para el canal.

La Universidad Tecnológica de Delft (TUD), junto con la fundación Imagine, de Holanda, y la Universidad Católica de Santiago de Guayaquil (UCSG) propusieron como solución a este problema, el uso de hormigón autorreparable reforzado con fibras naturales. Con la utilización de este innovador material se espera mejorar la sustentabilidad y funcionamiento de esta obra de irrigación y extender su vida útil.

Durante una inspección inicial del canal por parte de los investigadores de la UCSG, se pudo establecer que el agrietamiento se debía a diferentes motivos, entre ellos los más importantes eran: deslizamientos del terreno circundante, esfuerzos inducidos por vegetación, y ciclos de congelamiento y descongelamiento.

En la figura 2 se puede observar el aspecto general del canal y un detalle de uno de las grietas a lo largo de la pared del canal. También se advirtió la presencia de numerosas grietas por juntas frías. Puesto que el recubrimiento de hormigón de los canales no tiene ningún tipo de refuerzo, se decidió incrementar la capaci- 

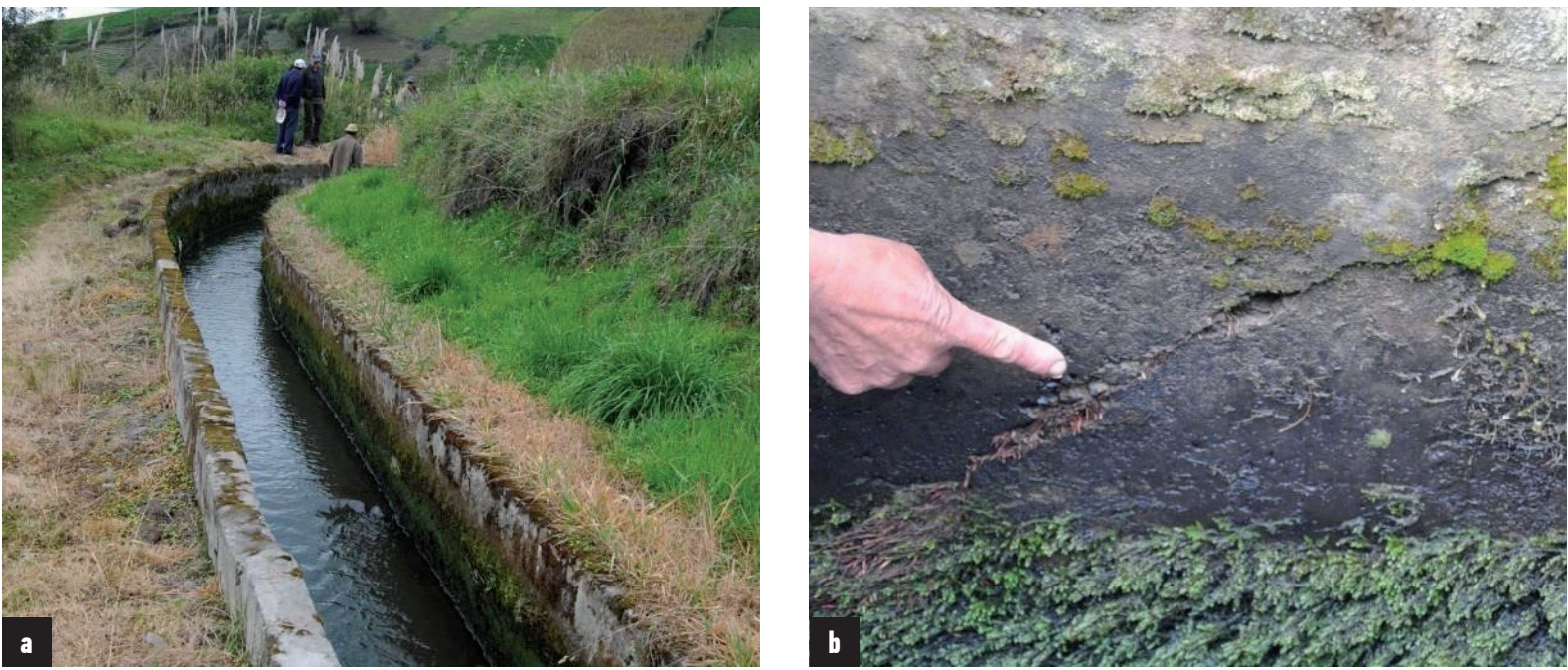

Figura 2. Inspección: a) Aspecto general del canal, b) Detalle de agrietamiento en la pared del canal.

dad a tensión del nuevo hormigón mediante la inclusión de fibras (Sierra Beltrán 2011). El uso de fibras en hormigón asegura un espesor de grieta controlada (Bentur y Mindness 2007). Las grietas con espesores controlados pueden autorepararse con más facilidad. Se seleccionó como refuerzo una fibra natural propia de Ecuador: abacá. Los investigadores de UCSG habían estudiado con éxito el uso de esta fibra para mejorar el comportamiento sísmico de viviendas de interés social (Mera Ortiz 2011).

INVESTIGACIÓN DE LABORATORIO

Tomando en cuenta la aplicación específica antes mencionada, los autores diseñaron un hormigón autoreparable teniendo en cuenta los materiales disponibles en el sitio de la aplicación, la provincia de Tungurahua, en Ecuador, así como también las demandas de esfuerzo y desempeño de la estructura. Se diseñó una mezcla de hormigón que fue ensayada primero en el laboratorio de TUD, Holanda. La mezcla incluyó grava, arena, cemento tipo Cem I 42.5N (estándar europeo), fibras naturales y arcillas expandidas impregnadas con bacterias y alimento para las bacterias. La grava tenía tamaño mínimo y máximo de 4 y $8 \mathrm{~mm}$, respectivamente. La arena tenía tamaño mínimo y máximo de 0.25 y $2 \mathrm{~mm}$, respectivamente.

El alimento seleccionado para la bacterias alcalifílicas consistió en lactato de calcio (80 gr/lt) y extracto de levadura (1 gr/lt) preparados en una solución que fue impregnada en las arcillas expandidas. De esta manera las arcillas impregnadas contienen $6 \%$ (en peso, en gramos) de alimento y 1.7 x 105 g-1 esporas de bacterias. Las partículas de arcilla expan- dida (Liapor R, Liapor $\mathrm{CmbH}$ Alemania) empleadas tienen diámetros entre 2 y $4 \mathrm{~mm}$. Se prepararon muestras con arcillas expandidas impregnadas y con arcillas expandidas sin impregnar (figura 3a).

Las fibras de abacá, también conocida como cáñamo de Manila, se obtienen del pseudotallo de la planta Musa Textilis. Esta planta es miembro de la familia Musacea a la que también pertenece la planta de plátanos. Las fibras de Abacá tienen una resistencia alta comparada con otras fibras naturales, son además flexibles, durables y tienen alta resistencia al agua salada (Barros-Cabezas 2008). En Ecuador estas fibras son extraídas para ser la materia prima en la fabricación de sogas. Para el refuerzo en hormigón, las fibras fueron cortadas a una longitud promedio de $2 \mathrm{~cm}$. En la mezcla de hormigón se añadieron fibras de Abacá con un contenido de $0.27 \%$ del peso total.

La resistencia a la compresión a 28 días de las muestras con bacterias es, en promedio, $30 \mathrm{MPa}$ mientras que la resistencia promedio de muestras sin bacterias es de $26 \mathrm{MPa}$ (Sierra Beltrán et al. 2013). La resistencia a la flexión fue evaluada por medio de pruebas de 3 puntos. La resistencia promedio a 28 días para muestras con bacterias es 5.7 MPa y para muestras sin bacterias es 5.4 MPa. Aun después de la falla de la muestra, las fibras de Abacá mantienen junta la grieta, tal como se muestra en figura 3b. La resistencia a compresión y flexión de las muestras con bacterias es mayor que las muestras sin bacterias debido a la presencia de lactato de calcio (alimento para las bacterias). Este efecto también fue descrito por Jonkers et al. (2010) y Sierra Beltrán et al. (2014a). 

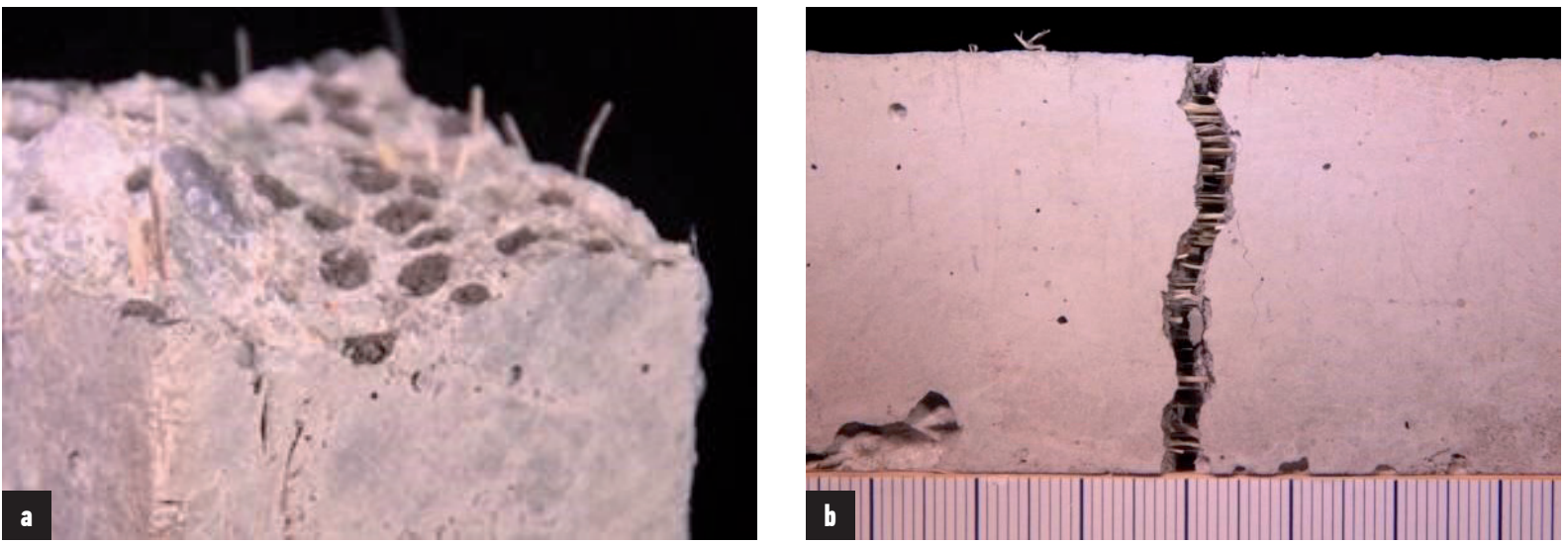

Figura 3. (a) Detalle de las partículas de arcilla expandida en una muestra de hormigón, (b) Fibras de Abacá mantienen junta la grieta incluso en una muestra ensayada hasta la falla.

A fin de evaluar la capacidad de autorreparación, mediante la prueba de flexión de tres puntos se produjo un agrietamiento de aproximadamente $140 \mu \mathrm{m}$ en muestras con y sin bacterias (figura 4a). Las muestras fueron entonces puestas con la cara agrietada en contacto con agua, simulando la misma situación que la pared del canal con agrietamiento. Observaciones en el microscopio mostraron cierre de las grietas después de seis semanas, tal como se puede apreciar en la figura 4b (Sierra Beltrán et al. 2013).

A fin de evaluar la capacidad de autorreparación, mediante la prueba de flexión de 3 puntos se produjo un agrietamiento de aproximadamente $140 \mu \mathrm{m}$ en muestras con y sin bacterias (figura 4a). Las muestras fueron entonces puestas con la cara agrietada en contacto con agua, simulando la misma situación que la pared del canal con agrietamiento. Observaciones en el microscopio mostraron cierre de las grietas después de 6 semanas tal como se puede apreciar en la figura 4b (Sierra Beltrán et al. 2013).

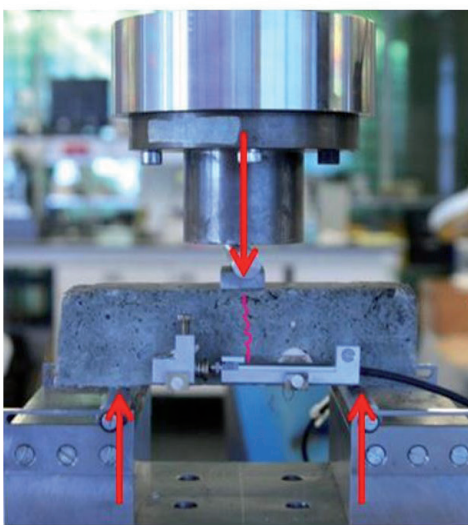

(a) Configuración de la prueba.

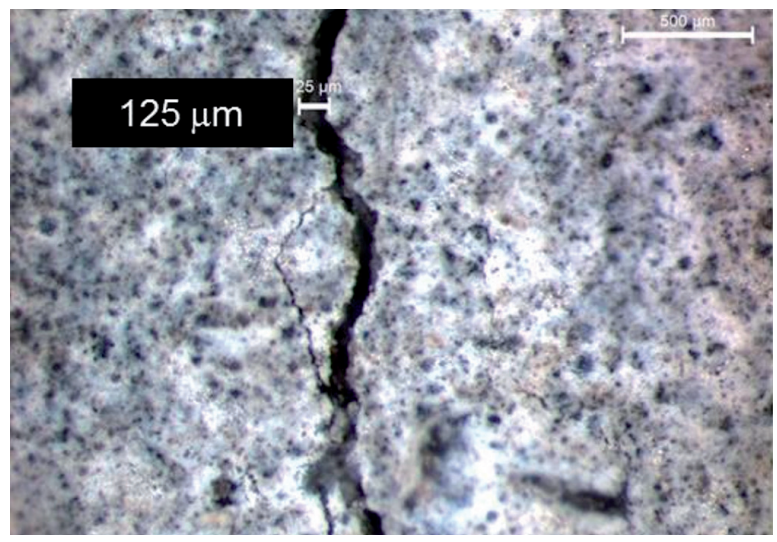

(a) Antes de auto-reparación.

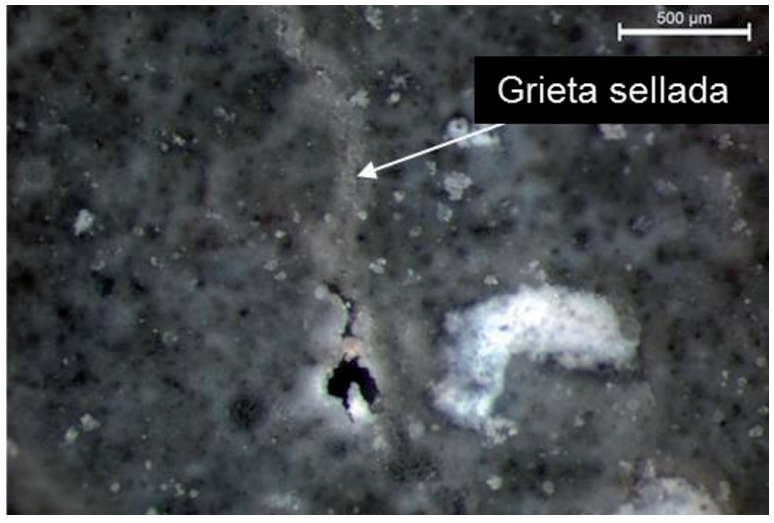

(a) Seis semana después.

Figura 5. (a) Foto de microscopio de la grieta en una muestra de concreto antes de la autorreparación, (b) Foto de la misma grieta seis semanas después, la grieta está sellada por la precipitación de carbonato de calcio.

(b) Reparación y precipitación en grietas. 
APLICACIÓN DE CAMPO EN ECUADOR

La aplicación de hormigón autorreparable en Ecuador se planificó para julio de 2014. Se seleccionó un tramo de canal que no tuviera aun recubrimiento de hormigón. El tramo seleccionado se encuentra a una altura de aproximadamente 2900 m.s.n.m. Se colarían dos tramos de canal, de tres metros lineales de longitud cada uno. Un tramo tendría hormigón autorreparable con arcillas expandidas impregnadas con bacterias y alimento para las bacterias y el otro tramo tendría hormigón con arcillas expandidas sin impregnar. El flujo de agua en el canal fue interrumpido en días previos y se realizó la limpieza del canal por parte de los agricultores. Esta actividad de mantenimiento tiene lugar dos veces al año.

Previo a la aplicación se realizaron pruebas de mezclado con los materiales disponibles en el sitio. El tamaño máximo de grava se incrementó a $10 \mathrm{~mm}$. En lugar de cemento Portland ordinario se utilizó cemento con un alto contenido de puzolanas. Adicionalmente, se cambió el superplastificante por uno disponible comercialmente en Ecuador. Debido a la presencia de fibras en la mezcla, es necesario utilizar una pequeña cantidad de superplastificante, a fin de asegurar la distribución uniforme de las fibras en la mezcla y la trabajabilidad de la misma. La consistencia y trabajabilidad de la mezcla son factores muy importantes a tener en cuenta cuando se trabaja con agregados ligeros, que tienden a segregarse. Con base en estos cambios, debió ajustarse la dosificación de la mezcla de hormigón. También se decidió cambiar la secuencia de mezclado a fin de acercarse lo más posible a la práctica común entre los agricultores, a fin que

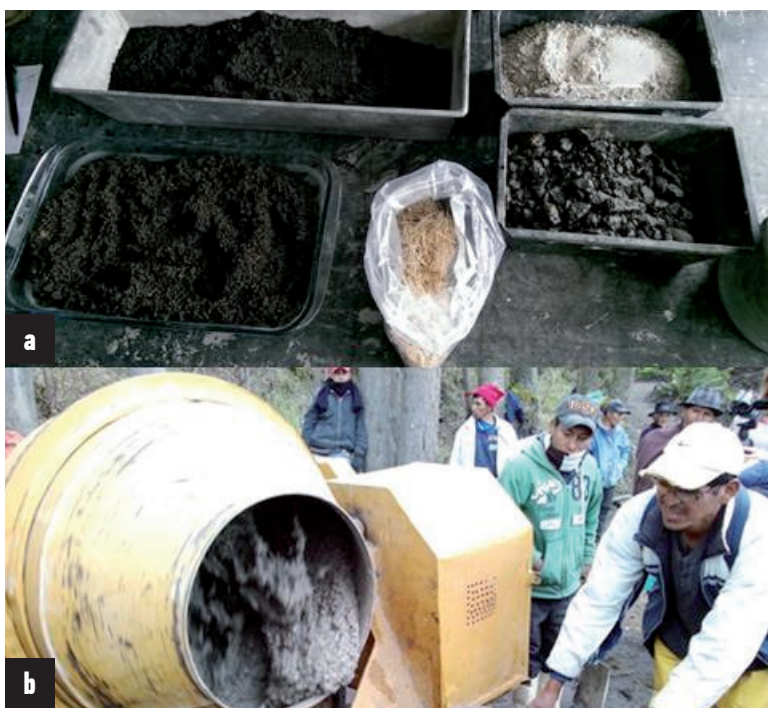

ellos pueden continuar aplicando el hormigón autorreparable. Sin embargo, los agricultores, en el sitio aprendieron de los investigadores a integrar a su mezcla fresca las partículas con agente de autoreparación y las fibras naturales.

En el sitio, el primer paso fue impregnar las arcillas expandidas con la solución de esporas de bacterias y alimento para las bacterias en la concretera. Para esta solución y para la mezcla de hormigón se empleó agua extraída del canal. Una vez impregnadas las arcillas se almacenaron en bolsas plásticas y se las dejaron descansar por unas horas. Mientras tanto, los agricultores construyeron el encofrado para las dos secciones de canal. La grava y arena, de extracción local, fue una contribución de los agricultores. Las fibras de abacá fueron previamente cortadas a una longitud aproximada de $2 \mathrm{~cm}$, en el laboratorio de la la UCSG. Se preparó un volumen de 110 litros de hormigón a la vez (figura 6b).

Tres días después de colado el hormigón se retiró el encofrado. No hubo evidencia de segregación del agregado ligero así como tampoco se notaron fibras naturales expuestas en la superficie del canal. Dos días después se reabrió el flujo de agua en el canal. Seis meses después, en la última inspección realizada por los investigadores de la UCSG no se registraron ni agrietamientos ni efectos de deterioro en el hormigón autorreparable (figura 6c).

\section{CONCLUSIONES}

El hormigón autorreparable con bacterias y fibras naturales fue exitosamente aplicado como recubrimiento de un canal de irrigación en la provincia de Tungurahua, en Ecuador,

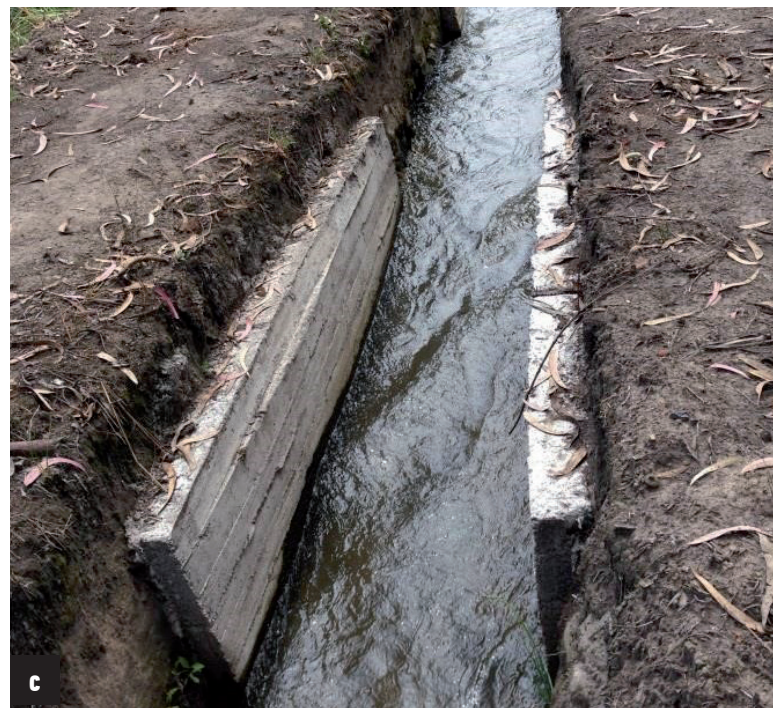

Figura 6. Dos tramos de prueba en Tungurahua, Ecuador: (a) Materiales en el sitio, (b) Mezcla del hormigón con apoyo de los agricultores, (c) Seis meses después, el flujo de agua en el canal no ha afectado la integridad de los tramos construidos. 
en 2014. Seis meses después del colado de este hormigón, durante una inspección en el sitio, no se registró ninguna evidencia de deterioro o agrietamiento. Para poder evaluar la capacidad de autorreparación es necesario esperar a que haya algún agrietamiento. En el laboratorio, muestras de este tipo de hormigón fueron agrietadas y luego de seis semanas expuestas al agua, las grietas se sellaron con depósitos con base de calcio.

\section{REFERENCIAS BIBLIOGRÁFICAS}

Ahn, T.H., Kishi, T. (2009) Crack healing behaviour of cementitious composite materials incorporating geomaterials. En S.White y I. Bond (eds), 2da Conferencia Internacional de Materiales Autoreparables; Memorias. Chicago, 28 Junio-1 Julio.

Ahn, T.H., Kishi, T. (2010) Crack self-healing behaviour of cementitious composites incorporating various mineral admixtures. Journal of Advanced Concrete Technology 8(2): 171-186.

Barros Cabezas, J. (2008) Hormigón reforzado con fibras vegetales. Tesis de grado, Universidad Católica de Santiago de Guayaquil, Ecuador. Bentur, A., Mindness, S. (2007) Fibre reinforced cementitious composites. New York: Taylor and Francis.

De Rooij, M.R, et al. (ed.) (2013) Self-healing phenomena in cement-based materials. Amsterdam: Springer Netherlands.

Dhami, N.K., Reddy, S.M., Mukherjee, A. (2012) Biofilm and microbial applications in biomineralized concrete. En: Seto, J. (ed), Advanced topics in biominerazilation: 137167. Rijeka: En Tech.

Edvarsen, C. (1999) Water permeability and autogenous healing of cracks in concrete. ACI Materials Journal 96 (4): 448-454.

Huang, H., Ye, G. (2011) Application of sodium silicate solution as self-healing agent in cementitious materials. En Leung, C. (ed), Conferencia Internacional en Avances en Materiales de Construcción a través de la Ciencia y la Ingeniería; Memorias. Hong Kong, 5-7 Septiembre. Rilem.

Huang, H. (2014) Thermodynamics of autogenous self-healing in cementitious materials. Tesis de Doctorado, Universidad Tecnologica de Delft, Holanda.

Jonkers, H.M. et al. (2010) Application of bacteria as self-healing agent in the development of sustainable concrete. Ecological Engineering 36: 230-235.
Debido al éxito de la aplicación del hormigón autorreparable, tanto los agricultores como las autoridades locales y los investigadores de la Universidad Católica de Santiago de Guayaquil (Ecuador) y de la Universidad Tecnológica de Delft (Holanda), esperan poder continuar aplicando este nuevo material en beneficio de la infraestructura y la comunidad.

Jonkers, H.M. (2011) Bacteria-based selfhealing concrete. Heron 56: 1-12.

Kim, J.S., Schlangen, E. (2011) Self-healing in ECC stimulated by SAP under flexural cyclic load. En I. Bond y R. Varley (eds), 3era Conferencia Internacional de Materiales Autorreparables; Memorias. Bath, 27- 29 Junio.

Mera Ortiz, W. 2011. Comportamiento sísmico de paredes de mampostería con refuerzo artificial y natural nometálico (in Spanish). Guayaquil: Universidad Católica de Santiago de Guayaquil.

Neville, A.M. (2002) Autogenous healing - A concrete miracle? Concrete International 24 (11): 76-82.

Palin, D., Wiktor, V., Jonkers, H.M. (2015) Autogenous healing of marine exposed concrete: Characterization and quantification through visual crack closure. Cement and Concrete Research, 73: 17-24.

Pelletier, M. et al. (2010) Self-healing concrete with a microencapsulated healing agent. Online.

Qian, S. et al. (2009) Self-healing behavior of strain hardening cementitious composites incorporating local waste materials. Cement \& Concrete Composites 31: 613-621.

Schlangen, E., Joseph, C. (2009) Self-healing processes in concrete, in S.K. Gosh (eds), Self-healing materials: Fundamentals, design strategies, and applications, 141-182. Weinheim: WILEY-VCH verlag $\mathrm{GmbH} \& \mathrm{Co}$, JGaA.

Sierra Beltrán, M.G. (2011) Ductile Cement-Based Composites with Wood Fibres. Tesis de Doctorado, Universidad Tecnológica de Delft.

Sierra Beltrán, M.G., Jonkers, H.M., Mera Ortiz, W. (2013) Concrete with Abaca fibres and bacteria to improve sustainability and performance of irrigation Canals in Ecuador. En R. Fangeuiro (ed) Conferencia Internacional de Fibras Naturales, Memorias. Guimaraes, 9-11 Junio.

Sierra Beltrán, M.G., Jonkers, H.M., Schlangen, E. (2014a) Characterization of 
sustainable bio-based mortar for concrete repair. Construction and Building Materials 67: 344-352.

Sierra Beltrán, M.G., Jonkers, H. M., Schlangen, E. (2014b) Performance of SHCC with bacteria for concrete patch repair. En: Forde M.C. (ed), Fallas Estructurales y Reparación; Memorias. Londres, 6-8 Julio.

Snoeck, D. et al. (2012) The use of superabsorbent polymers as a crack sealing and crack healing mechanism in cementitious materials. En Alexander, A. et al. (eds), 3era Conferencia Internacional en Reparación, Rehabilitación y Reconversión de Hormigón; Memorias. Cd del Cabo, 3-5 Septiembre. Leiden: Balkema.

Spanka, R., Fritze, D. (1993) Bacillus cohnii sp. nov. , a new obligately alkaliphilic, oval-spore-forming bacillus species with ornithine and aspartic acid instead of diaminopimelic acid in the cell wall. International Journal of Syst Bacteriol 43(1): 150-156.

Van Tittelboom, K. et al. (2010) Use of bacteria to repair cracks in concrete. Cement and Concrete Research 40: 157-166.

Wang, J. (2013) Self-healing concrete by means of immobilized carbonate precipitating bacteria. $\mathrm{Te}^{-}$ sis de Doctorado, Universidad de Gantes, Bélgica.

Wiktor, V., Jonkers, H.M. (2011) Quantification of crack-healing in novel bacteria-based self-healing concrete. Cement $\&$ Concrete Composites 33: 763-770.

Yang, Y., Lepech, M.D., Yang, E. Li, V.C. (2009) Autogenous healing of engineered cementitious composites under wet-dry cycles. Cement and Concrete Research 39: 382390. 